\title{
GRP78 Participates in PCA3-regulated Prostate Cancer Progression
}

\author{
CHUNHUA LIN $^{1 *}$, JIAHUI WANG ${ }^{2 *}$, YANWEI WANG ${ }^{2}$, PENG ZHU ${ }^{2}$, XIN LIU $^{2}$, \\ NING LI $^{2}$, JUAN LIU ${ }^{2}$, LUXIN YU ${ }^{1}$ and WENTING WANG ${ }^{2}$ \\ ${ }^{1}$ Department of Urological Surgery, The Affiliated Yantai Yuhuangding Hospital of Qingdao University, Yantai, P.R. China; \\ ${ }^{2}$ Central Laboratory, The Affiliated Yantai Yuhuangding Hospital of Qingdao University, Yantai, P.R. China
}

\begin{abstract}
Background/Aim: The human prostate cancer antigen 3 (PCA3) is a long non-coding RNA (IncRNA) commonly used as a diagnostic marker for prostate cancer $(P C a)$. Herein we investigated the cellular function of PCA3 in PCa and its potential mechanism. Materials and Methods: $P C A 3$ was overexpressed in a $P C 3$ cell line $\left(P C 3^{P C A+}\right)$ and cell proliferation, migration, invasion and apoptosis were compared to those of control cells $\left(P C 3^{N C}\right)$. Differentially expressed proteins were identified by two-dimensional polyacrylamide gel electrophoresis (2D-PAGE) and mass spectrometry. Results: Overexpression of PCA3 significantly increased cell proliferation rate, migration and invasion, while inhibited apoptosis in PC3 cells. Three proteins were found down-regulated and 7 proteins up-regulated in $P C 3^{P C A+}$ cells compared to $P C 3^{N C}$ cells, including GRP78. Higher GRP78 was also found in PCa clinical specimens. Conclusion: This study confirmed that in PCa, PCA3 plays a pro-cancer role through promoting cell proliferation, migration and invasion while inhibiting cell apoptosis. This process might involve the up-regulation of GRP78.
\end{abstract}

Prostate cancer (PCa) is a common malignancy affecting the male urogenital tract, which imposes a severe threat to human life. In 2012, there were 1,100,000 patients diagnosed with $\mathrm{PCa}$ worldwide, with $75 \%$ occurring in developed

\footnotetext{
*These Authors contributed equally to this study.

Correspondence to: Luxin $\mathrm{Yu}, \mathrm{MD}$, Department of Urological Surgery, The Affiliated Yantai Yuhuangding Hospital of Qingdao University, 20 Yuhuangding East Road, Yantai, Shandong, 264000, P.R. China. Tel: +86 5356691999, e-mail: 2016499173@qq.com and Wenting Wang, MSc, Central Laboratory, The Affiliated Yantai Yuhuangding Hospital of Qingdao University, 20 Yuhuangding East Road, Yantai, Shandong, 264000, P.R. China. Tel: +86 5356691999 e-mail: wwting_78@163.com
}

Key Words: Prostate cancer, PCA3, GRP78, long non-coding RNA, cancer-related genes. countries, especially Australia, New Zealand and the United States (1). There are 180,890 estimated new cases in the United States in 2016 and it potentially causes 26,120 deaths, which accounts for about $1 / 5$ of new cancer diagnosis in men (2). In China, there were 603,000 estimated new cases of PCa in 2015 , leading to 266,000 deaths. Due to the aging of population and development in diagnosis, the incidence of PCa has been constantly rising in the past 15 years (3).

Although novel therapies with proven survival benefits have been developed in the last few years (4), the increases in survival rates are marginal. The prostate-specific antigen (PSA) screening and histopathological grading performed by Gleason scoring have been used as important prognostic indicators of $\mathrm{PCa}$ (5). A major clinical challenge in $\mathrm{PCa}$ is the inability of current diagnostic tests to distinguish between aggressive and indolent tumors (6). Novel biomarkers of PCa have been studied during recent years with the aim of increasing the diagnostic specificity and sensitivities. The human prostate cancer antigen 3 ( $P C A 3$, previously known as $D D 3$ ) is a long non-coding RNA (lncRNA) specifically expressed in human prostate (7). It is $25 \mathrm{~kb}$ long, containing 3 introns and 4 exons (8). Although the $P C A 3$ gene does not encode any protein, its mRNA is identified to be overexpressed 60 to 100 -fold in $95 \%$ of PCa cells, while little or no expression is observed in normal prostate tissue or benign prostatic hyperplasia $(9,10)$. A wide variety of studies confirmed the diagnostic value of serum and urine PCA3 in predicting PCa and PCA3 was approved by the FDA in 2012 as an important diagnostic marker for PCa (11). Compared to the traditional PCa biomarker prostate-specific antigen (PSA), PCA3 score, even when the most appropriate cut-off has to be established, performs better than PSA, although its relationship with the aggressiveness of the tumor remains controversial (12).

However, despite its robust clinical application, the role that PCA3 plays in the tumorigenesis and development of $\mathrm{PCa}$ is not very clear. Ferreira et al. reported that PCA3 may modulate PCa cell survival and that PCA3 expression is androgen-regulated via activation of androgen receptor 
(AR)-mediated signaling (13). A recent study found that down-regulation of PCA3 modulated the expression of several key cancer-related genes in PCa cells, including those coding for AR cofactors and epithelial-mesenchymal transition (EMT) markers, as well as leading to loss of viability of the cells (14). However, our understanding of the biological function and regulatory mechanism of PCA3 are still superficial.

In this study, we further characterized the cellular function of PCA3 in PCa and identified a potential effector of PCA3 through proteome analysis, which provided a clue for the mechanism of how PCA3 is involved in PCa.

\section{Materials and Methods}

Cell culture. PC3 prostate cancer cell lines were obtained from ATCC (Rockville, MD, USA) and cultured in RPMI-1640 medium (Gibco, Grand island, NY, USA) supplemented with $10 \%$ fetal bovine serum (Gibco) at $37^{\circ} \mathrm{C}$ in $5 \% \mathrm{CO}_{2}$ humidified incubator. Cells were harvested in logarithmic phase of growth for all experiments described below.

Plasmid construction and transfection. PCA3 overexpression vector pcDNA3.1(+)-PCA3 was constructed by amplifying PCA3 with primers 5'-AGATTTGTGTGGCTGCAGC-3' and 5'-TCCTGCCC ATCCTTTAAGG-3' using a synthesized $P C A 3$ sequence (GenBank number NR_015342.2) as template, which was inserted into the pcDNA3.1(+) vector. For plasmid transfection, cells were seeded in 6-well plate and cultured overnight to reach $70-80 \%$ confluency. Recombinant plasmid or empty vector was transfected into cells using X-treme GENE HP DNA transfection reagent (Roche, Indianapolis, IN, USA), according to the manufacturer's instructions. Cells were examined $48 \mathrm{~h}$ after transfection under an inverted fluorescence microscope to assess transfection efficiency. Cells were then harvested and subjected to following analyses.

RNA isolation and quantitative real-time polymerase chain reaction ( $q R T-P C R)$. Total RNA was extracted from cells using RNAiso Plus reagent (TaKaRa, Dalian, China), according to the manufacturer's instructions. The concentration of RNA was determined by spectrophotometry (Nanodrop 2000/2000C; Thermo Scientific, Shanghai, China). Then, $2 \mu \mathrm{g}$ total RNA was reverse transcribed using ReverTra Ace (TOYOBO, Shanghai, China). qRT-PCR analysis was performed on a Roter-Gene Q (QIAGEN, Hilden, Germany) with the Platinum SYBR Green qPCR SuperMix-UDG kit (Life Technologies Corporation, Carlsbad, CA, USA), according to the manufacturer's protocol. Cycling conditions were: $50^{\circ} \mathrm{C}$ for $2 \mathrm{~min} ; 95^{\circ} \mathrm{C}$ for $5 \mathrm{~min}$; followed by 40 cycles of $95^{\circ} \mathrm{C}, 10 \mathrm{~s}$ and $60^{\circ} \mathrm{C}, 45 \mathrm{~s}$. Melting curve analysis and agarose gel electrophoresis were used to confirm the specific PCR products. Glyceraldehyde 3-phosphate dehydrogenase $(G A P D H)$ was used as endogenous reference.

Cell proliferation assay. Cells were seeded into 96-well plates at a density of $5 \times 10^{3}$ cells/well and cultured overnight. Cell proliferation was measured using the CCK-8 assay (Biyuntian, Shanghai, China) in $24 \mathrm{~h}$ increments for up to $96 \mathrm{~h}$. In brief, 10 $\mu \mathrm{l}$ CCK- 8 solution was added into each well of cell culture and the plates were further incubated for another $2.5 \mathrm{~h}$. Optical density was then measured by FACS analysis at the absorbance of $450 \mathrm{~nm}$. Experiments were performed in triplicate and repeated at least three times independently.

Wound healing assay. When transfected cells reached 95\% confluence in 6-well plates after transfection, a $200 \mu$ pipette tip was used to draw a straight wound with the same width on the cell monolayer. After washing with phosphate buffered saline (PBS) and removing cell debris, the cells were cultured using a serum-free medium under standard conditions. The wound was observed under a light microscope (Olympus Corporation, Tokyo, Japan) at $40 \times$ magnification at two preselected time points $(0$ and $24 \mathrm{~h})$. The widths of the wounds in each well were measured.

Migration and invasion assays. Cell migration and invasion were determined using a transwell chamber $(8 \mu \mathrm{m}$ pore size $)$ with and without BD Matrigel (BD Biosciences, San Jose, CA, USA). The upper side of the membrane was coated with Matrigel for the invasion assay. After $24 \mathrm{~h}$ of transfection, a total of $1 \times 10^{5}$ cells in $200 \mu \mathrm{l}$ serum-free medium were plated to the upper chambers and $600 \mu \mathrm{l}$ medium containing 10\% FBS was used as a chemoattractant in the lower chambers. After $48 \mathrm{~h}$, the cells on the upper side of the membrane were removed using cotton swabs, whereas the invaded cells on the lower side of the membrane were fixed, stained and counted using an inverted microscope at $400 \times$ magnification.

Annexin V fluorescein isothiocyanate (FITC)/propidum iodide (PI) double staining. An Annexin V FITC Apoptosis Detection kit (BD Biosciences) was used to assess the apoptosis of transfected cells. PC3 cells, which were transfected for $48 \mathrm{~h}$, were collected and washed with PBS. Subsequently, the cells were resuspended in $1 \mathrm{X}$ Binding Buffer at a density of $1 \times 10^{6}$ cells $/ \mathrm{ml}$. In total, $5 \mu$ l Annexin V FITC and $5 \mu \mathrm{l}$ PI were added to the cells, which were incubated at room temperature for $15 \mathrm{~min}$. Subsequently, the cells were analyzed by flow cytometry, using BD FACSDiva ${ }^{\mathrm{TM}}$ software v6.1.3 and BD CellQuest ${ }^{\mathrm{TM}}$ Pro (BD Biosciences).

Gel electrophoresis, mass spectrometry and protein identification. The procedure of 2D-polyacrylamide gel electrophoresis (2DPAGE) was performed as described previously (15). All gels were stained with Coomassie brilliant blue R-350 (Amersham Biosciences, Uppsala, Sweden). Gels were made in triplicate to confirm the spot patterns and scanned with a Z320 scanner (Founder, Beijing, China). Gel images were analysed with Imagemaster software version 6.0 (GE Healthcare, Piscataway, NJ, USA). For quantification, each gel was normalized by the volume of its each spot divided by the total volume of all spots. Quantitative analysis was performed by Student's $t$-test. Protein spots were excised from gels and destained with $25 \mathrm{mM} \mathrm{NH}_{4} \mathrm{HCO}_{3} 50 \%(\mathrm{v} / \mathrm{v})$ acrylonitrile. After drying, $10 \mathrm{ng}$ trypsin in $10 \mathrm{ml}$ of $25 \mathrm{mM}$ $\mathrm{NH} 4 \mathrm{HCO} 3$ was added for digestion for $12 \mathrm{~h}$ at $37^{\circ} \mathrm{C}$. Peptides were analysed on a 5800 MALDI-TOF/TOF MS (Applied Biosystems/ MDS SCIEX, Framingham, MA, USA). Mass spectrometry data were analysed automatically by GPS Explorer software (version 3.6; Applied Biosystems) integrated with Mascot version 2.1 (Matrix Science, Boston, MA, USA) against the SWISS-PROT protein database (SwissProt Release 55.0, 356194 sequences, 127836513 residues) for Homo sapiens. For tandem mass spectrometry 
Table I. Summary of differentially expressed proteins between $P C 3^{P C A 3}+$ and $P C 3^{N C}$ cells identified by mass spectrometry.

\begin{tabular}{|c|c|c|c|c|c|c|c|}
\hline Spot No. & $\begin{array}{c}\mathrm{PC}^{\mathrm{PCA} 3+/} \\
\mathrm{PC}^{\mathrm{NC}}\end{array}$ & $\begin{array}{l}\text { Protein } \\
\text { name }\end{array}$ & $\begin{array}{l}\text { Gene } \\
\text { name }\end{array}$ & $\begin{array}{c}\text { Swiss-Prot } \\
\text { Accession No. }\end{array}$ & MW & PI & $\begin{array}{c}\text { Protein } \\
\text { score }\end{array}$ \\
\hline \multicolumn{8}{|c|}{ Structural constituent of cytoskeleton } \\
\hline 8 & $2.03 \pm 0.06$ & Keratin, type I cytoskeletal 19 & KRT19 & P08727 & 44,065 & 5.05 & 238 \\
\hline 9 & $2.60 \pm 0.11$ & Keratin, type I cytoskeletal 18 & KRT18 & P05783 & 48,029 & 5.34 & 80 \\
\hline 3 & $3.08 \pm 0.15$ & type I cytoskeletal 10 & KRT10 & P13645 & 59,020 & 5.13 & 110 \\
\hline \multicolumn{8}{|l|}{ Binding } \\
\hline 7 & $0.46 \pm 0.03$ & Vimentin & $V I M$ & $\mathrm{P} 08670$ & 53,676 & 5.05 & 411 \\
\hline 10 & $2.83 \pm 0.02$ & Calreticulin & $C A L R$ & P27797 & 48,283 & 4.29 & 109 \\
\hline 4 & $0.39 \pm 0.05$ & Alpha-enolase & ENO1 & P06733 & 47,481 & 7.01 & 194 \\
\hline \multicolumn{8}{|c|}{ Chaperone } \\
\hline 1 & $3.36 \pm 0.03$ & $78 \mathrm{kDa}$ glucose- regulated protein & GRP78 & P11021 & 72,402 & 5.07 & 157 \\
\hline 5 & $2.04 \pm 0.03$ & $60 \mathrm{kDa}$ heat shock protein & $H S P D 1$ & P10809 & 61,187 & 5.70 & 583 \\
\hline \multicolumn{8}{|l|}{ Isomerase } \\
\hline 2 & $0.43 \pm 0.08$ & Triosephosphate isomerase & TPII & P60174 & 26,938 & 5.65 & 96 \\
\hline \multicolumn{8}{|c|}{ Antioxidant ctivity } \\
\hline 6 & $2.01 \pm 0.07$ & Protein isulfide- isomerase A3 & PDIA3 & P30101 & 57,146 & 5.98 & 99 \\
\hline
\end{tabular}

MW, Molecular weight; PI, isoelectric point.

(MS/MS) database searches, the mass tolerance of precursor ions and fragment ions was set to $150 \mathrm{ppm}$ and $0.4 \mathrm{Da}$. The MS/MS analysis score was $>60(p<0.05)$. If one spot corresponded to more than one protein, the top-ranked protein in each spot was singled out from the multi protein family.

Protein extraction and western blotting. Total cellular protein was extracted from transfected cells and protein concentration was determined using a BCA protein assay kit (Beyotime, Beijing, China). These protein samples were resolved in 10\% SDS denatured polyacrylamide gel and transferred onto polyvinylidene difluoride (PVDF) membranes with a pore size of $0.45 \mu \mathrm{m}$ (Millipore, Billerica, MA, USA). After blocking in 5\% skim milk in Tris-based saline-Tween 20 (TBST) for $60 \mathrm{~min}$ at room temperature, membranes were incubated with rabbit anti-hGRP78 antibodies at a dilution of 1:1,000 (all antibodies from Abcam, Cambridge, MA, USA) overnight at $4^{\circ} \mathrm{C}$. After washed in TBST, the membranes were further incubated with a secondary goat antirabbit $(1: 5,000)$ antibody for $1 \mathrm{~h}$. Enhanced chemiluminescence (ECL) solution was added onto the membranes and protein expression was quantified using The Laboratory Work Image Acquisition and Analysis Software (UVP, Upland, CA, USA). Actin was used as a loading control.

Immunohistochemical staining. Formalin-fixed tissue samples were embedded in paraffin and sliced into $4 \mu \mathrm{m}$ sections. Immunohistochemical staining was performed as previously described (16). Briefly, the tumor tissue sections were deparaffinized, rehydrated and stained with anti-hGRP78 primary antibody (Santa Cruz Biotechnology, Santa Cruz, CA, USA) and biotin-labeled secondary antibody (Zhongshan Golden Bridge Biotechnology Co., Ltd., Beijing, China), followed by incubation with diaminobenzidine (Zhongshan Golden Bridge Biotechnology Co., Ltd.) and counterstained with hematoxylin. Slides were dehydrated with various concentrations of ethanol and soaked in xylene and then mounted with neutral balsam and visualized using a light microscope (DM LB2; Leica, Nussloch, Germany).
Statistical analyses. The results are expressed as mean \pm standard deviation. All statistical analyses were performed using the SPSS 16.0 software (SPSS Inc., Chicago, IL, USA). Data were analyzed using a two-tailed Student's $t$-test or one-way analysis of variance. $p<0.05$ was considered statistically significant.

\section{Results}

PCA3 promoted cell proliferation, migration and invasion, while inhibited apoptosis in PC3 cells. In order to study the role of $\mathrm{PCA} 3$ in $\mathrm{PCa}$, we overexpressed PCA3 from pcDNA3.1(+) vector in the PCa cell line PC3. Expression of PCA3 was measured on transcription level by qPCR. PC3 cells harboring the $\mathrm{PCA} 3$ overexpression vector $\left(\mathrm{PC}^{\mathrm{PCA} 3+}\right)$ had significantly increased expression of $P C A 3$ comparing to the control cells that were transfected with the empty vector $\left(\mathrm{PC} 3^{\mathrm{NC}}\right.$ ) (Figure $\left.1 \mathrm{~A}, p<0.01\right)$.

We further investigated the changes in cell behavior upon $P C A 3$ overexpression in PC3 cells. Cell proliferation assay were performed on $\mathrm{PC} 33^{\mathrm{PCA} 3+}$ and $\mathrm{PC} 3^{\mathrm{NC}}$ cells and we found significantly higher proliferation rate in $\mathrm{PC} 3^{\mathrm{PCA} 3+}$ cells beginning at day 1 (Figure1B). Cell migration and invasion was studied by wound healing assay and migration, as well as invasion, assays. Wound healing assay demonstrated significantly increased cell mobility in PC3 cells overexpressing PCA3 (Figure 1C and D). Similarly, the migration and invasion assay showed that PCA3 significantly promoted the migration and invasion abilities of PC3 cells (Figure 1E and F). These results suggested that $\mathrm{PCA} 3$ contributed to the proliferation, migration and invasion of $\mathrm{PC} 3$ cells.

Subsequently, the effect of PC3 on cell apoptosis was analyzed using Annexin V and PI double staining. The proportion of Annexin $\mathrm{V}$ positive early phase apoptotic cells 

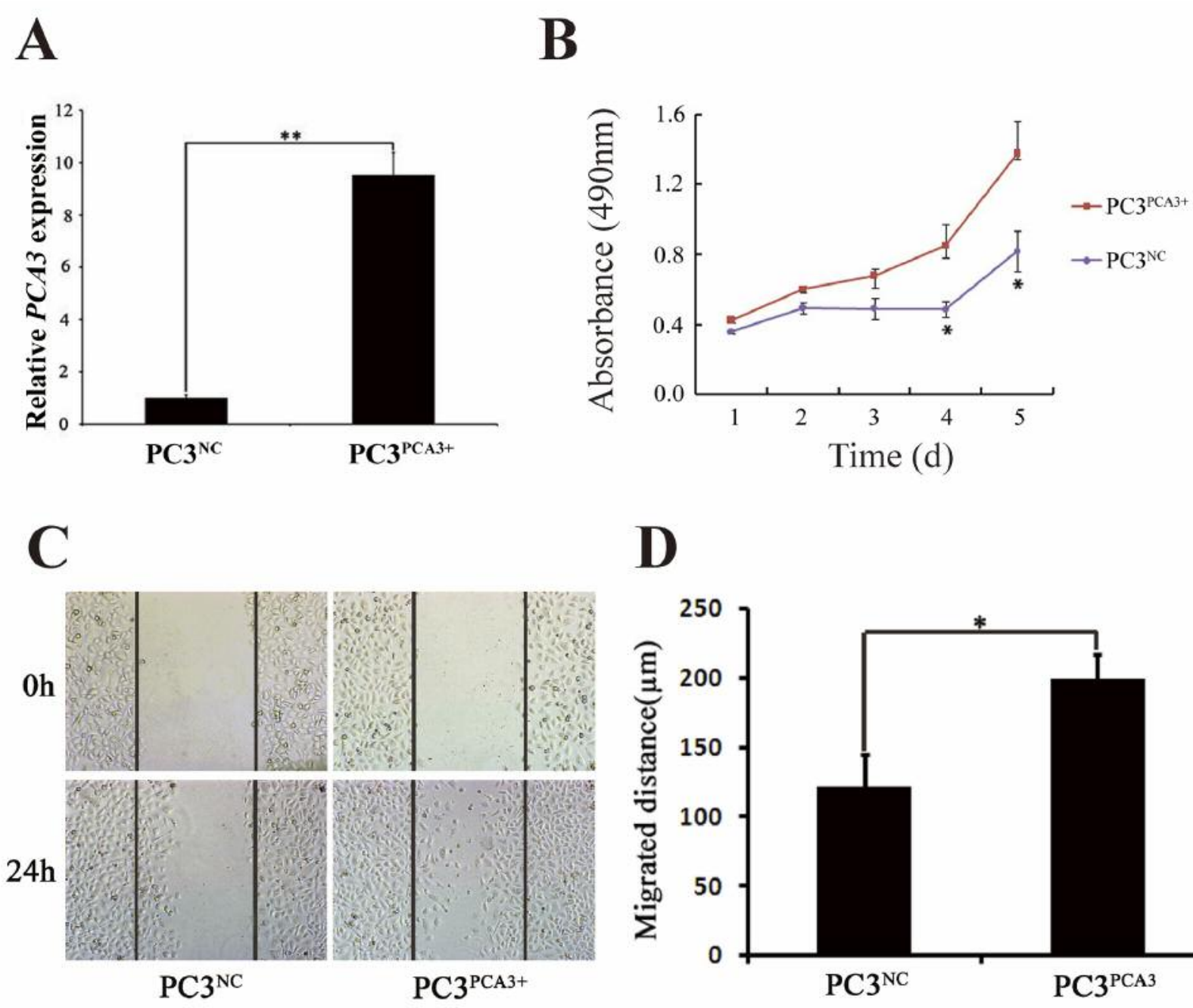

D

E
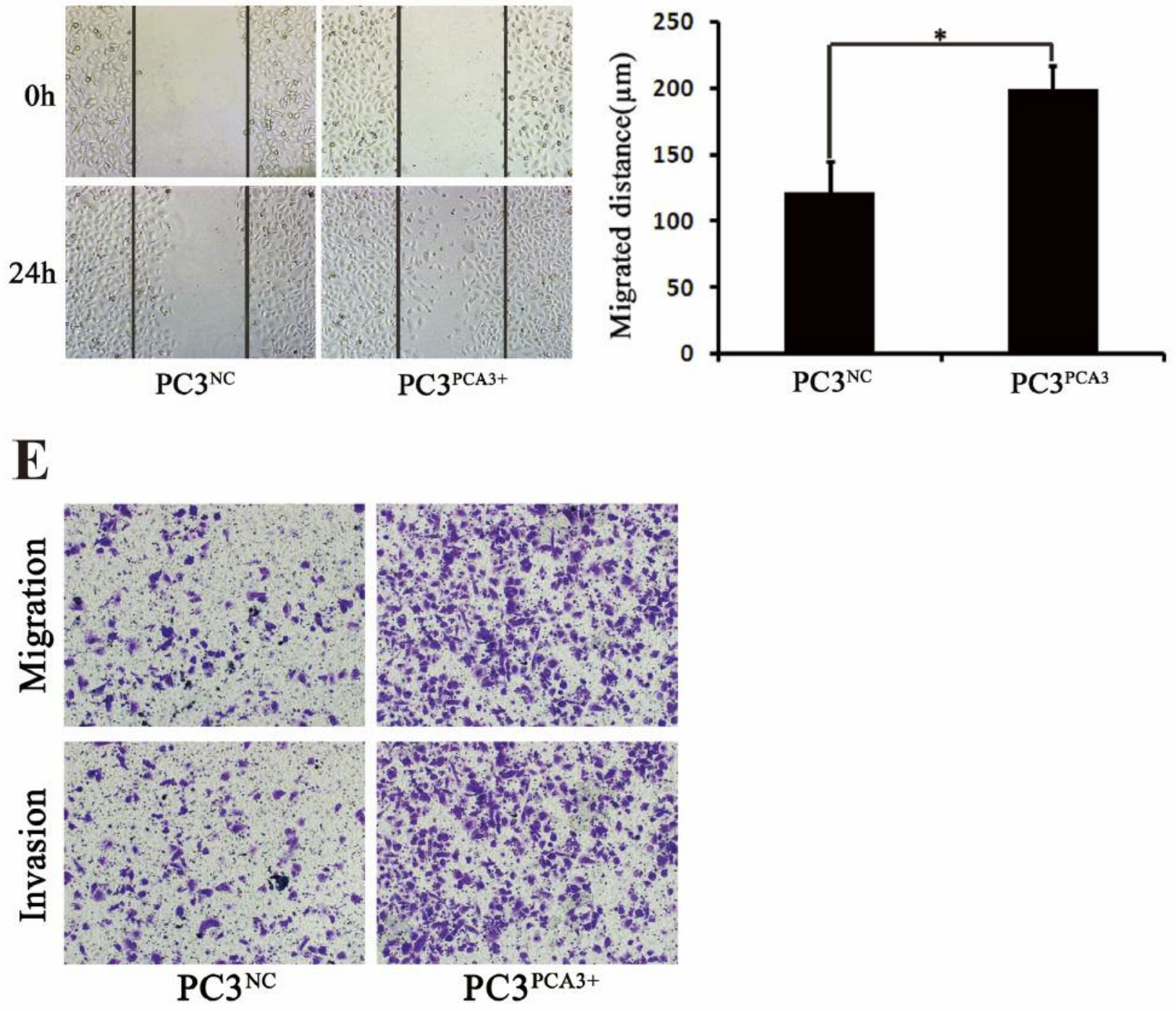

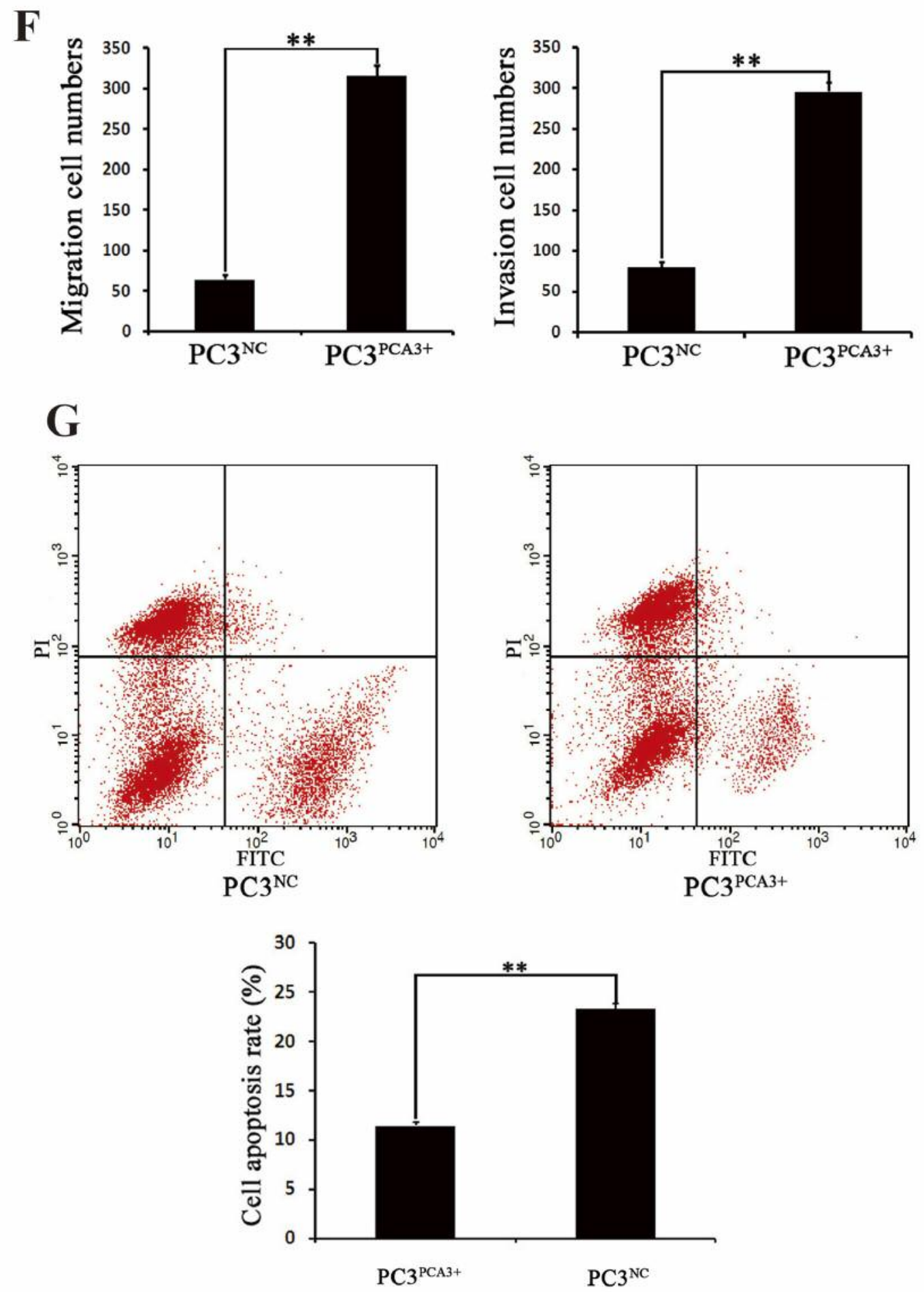

Figure 1. Overexpression of PCA3 led to increased proliferation, migration, invasion and decreased apoptosis of PC3 cells. (A) Quantitative realtime polymerase chain reaction ( $q R T-P C R)$ analysis of PCA3 expression in transfected PC3 cells. PC 3 cells were grown and transfected with pcDNA3.1(+)-PCA3 $\left(P C 3^{P C A 3+}\right)$ or pcDNA3.1(+) vector $\left(P C 3^{N C}\right)$ and subjected to $q R T-P C R$ analysis.** $<<0.01 .(B)$ MTT assay showing increased PC3 cell proliferation when overexpressing PCA3. ${ }^{*} p<0.05$. (C) Representative images of the wound healing assay. A 200- $\mu$ l pipette tip was used to draw a straight wound with the same width on the cell monolayer. The wound was observed at $40 \times$ magnification at 0 and 24 h. (D) Quantitative comparison of cell motility between PC $3^{P C A 3+}$ and $P C 3^{N C}$ cell. ${ }^{*} p<0.05$. (E) Representative images of the migration and invasion assay. ( $F$ ) Quantitative comparison of cell migration and invasion between $P C 3^{P C A 3+}$ and $P C 3^{N C}$ cells. $* * p<0.01 .(G)$ Flow cytometry result showing decreased apoptosis rate in PC3 cells overexpressing PCA3. 

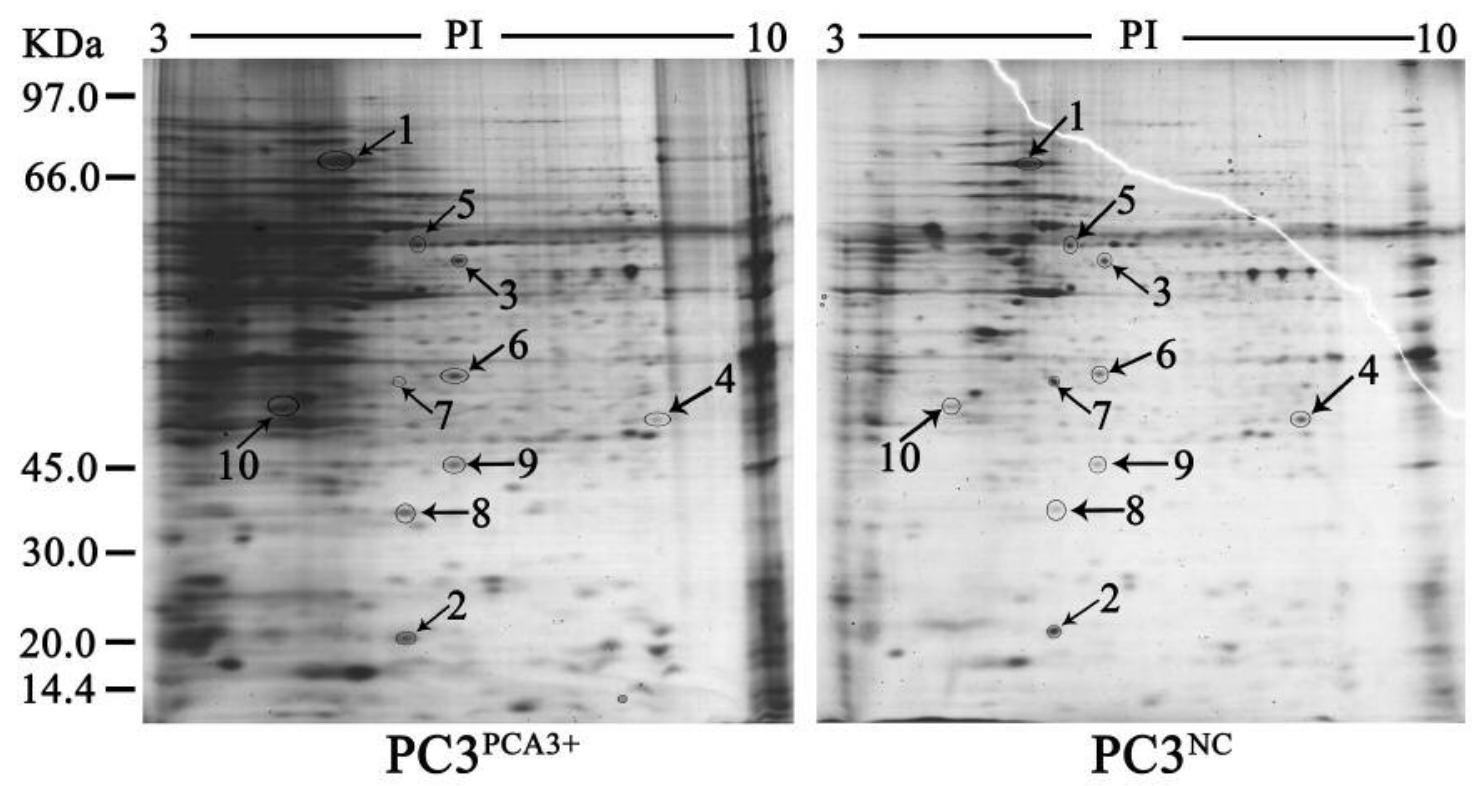

Figure 2. Separation and identification of differentially expressed proteins between $P C 3^{P C A 3+}$ and $P C 3^{N C}$ cells by two-dimensional polyacrylamide gel electrophoresis (2D-PAGE).

was significantly decreased in $\mathrm{PC}^{\mathrm{PCA} 3+}$ cells $(11.43 \% \pm 0.32 \%)$ compared to $\mathrm{PC} 3{ }^{\mathrm{NC}}$ cells $(23.30 \% \pm 0.52 \%, p<0.01$, Figure $1 \mathrm{G}$ and $1 \mathrm{H})$. This suggested that PCA3 played an anti-apoptosis role in $\mathrm{PCa}$.

Identification of differentially expressed proteins between $P C 3^{P C A 3+}$ and $P C 3^{N C}$ cells. Using 2D-PAGE and mass spectrometry, we investigated the differentially expressed proteins between $\mathrm{PC}_{3}{ }^{\mathrm{PCA} 3+}$ and $\mathrm{PC} 3{ }^{\mathrm{NC}}$ cells. A total of 10 differentially expressed proteins were identified, including 7 proteins that were up-regulated (ratio $\mathrm{PC}_{3}{ }^{\mathrm{PCA} 3}{ }^{+}: \mathrm{PC}{ }^{\mathrm{NC}} \geq 2$; $p<0.01)$ and 3 proteins down-regulated in the $\mathrm{PC}_{3}{ }^{\mathrm{PCA} 3+}$ cells (ratio $\mathrm{PC}{ }^{\mathrm{PCA} 3+}: \mathrm{PC}{ }^{\mathrm{NC}} \leq 0.5 ; p<0.01$ ). (Table I, Figure 2). The one up-regulated protein in $\mathrm{PC}_{3}{ }^{\mathrm{PCA} 3+}$ with the highest foldchange was the $78 \mathrm{kD}$ glucose-regulated protein (GRP78).

GRP78 was up-regulated in PCa. To confirm the upregulation of GRP78 upon PCA3 overexpression, the protein levels of GRP78 in $\mathrm{PC}_{3}{ }^{\mathrm{PCA} 3+}$ and $\mathrm{PC}_{3}{ }^{\mathrm{NC}}$ cells were measured and a significantly higher level of GRP78 was found in $\mathrm{PC}_{3}{ }^{\mathrm{PCA} 3+}$ cells than in $\mathrm{PC}^{\mathrm{NC}}$ cells (Figure $3 \mathrm{~A}$ ). In PCa clinical specimens, immunohistochemistry showed stronger GRP78 staining in the tumorous tissues compared with the normal para-carcinoma tissue (Figure 3B).

\section{Discussion}

Despite the robust clinical application of PCA3 in the diagnosis of $\mathrm{PCa}$, the mechanism of PCA3 in association with PCa has not been widely studied. Lemos et al. knockeddown PCA3 in another PCa cell line, LNCaP, which led to loss of cell viability (14). In this study, we elucidated the cellular function of PCA3 in the PCa cell line PC3 by overexpressing PCA3. PCA3 was confirmed to increase cell proliferation, promote cell migration and invasion and suppress cell apoptosis of PC 3 cells.

We then investigated possible mechanism of the pro-tumor effect of PCA3 via proteomic analysis and identified several potential effector proteins of PCA3. Among these effector proteins, GRP78 seemed to be markedly positively regulated by PCA3.

GRP78 is also known as binding immunoglobulin protein (BiP) $(17,18)$. It is considered the master regulator of the unfolded protein response (UPR) (19), which is triggered by the accumulation of unfolded protein within the endoplasmic reticulum (ER) that initiates a widespread but refined signaling cascade (20).

There have been numerous, yet inconsistent, reports regarding the association of GRP78 with cancers. Some studies have reported the pro-cancer effect of GRP78. GRP78 increase and UPR activation following ER stress were identified as mechanisms favoring growth and invasion of endometrial cancer cells (21). GRP78 was also reported to play a crucial role in the proliferation, migration and invasion of pancreatic cancer cells and may be a suitable prognostic marker in pancreatic ductal adenocarcinoma (22). In contrast, other studies suggested GRP78 as an anti-tumor factor. For example, reduced expression of GRP78 was 


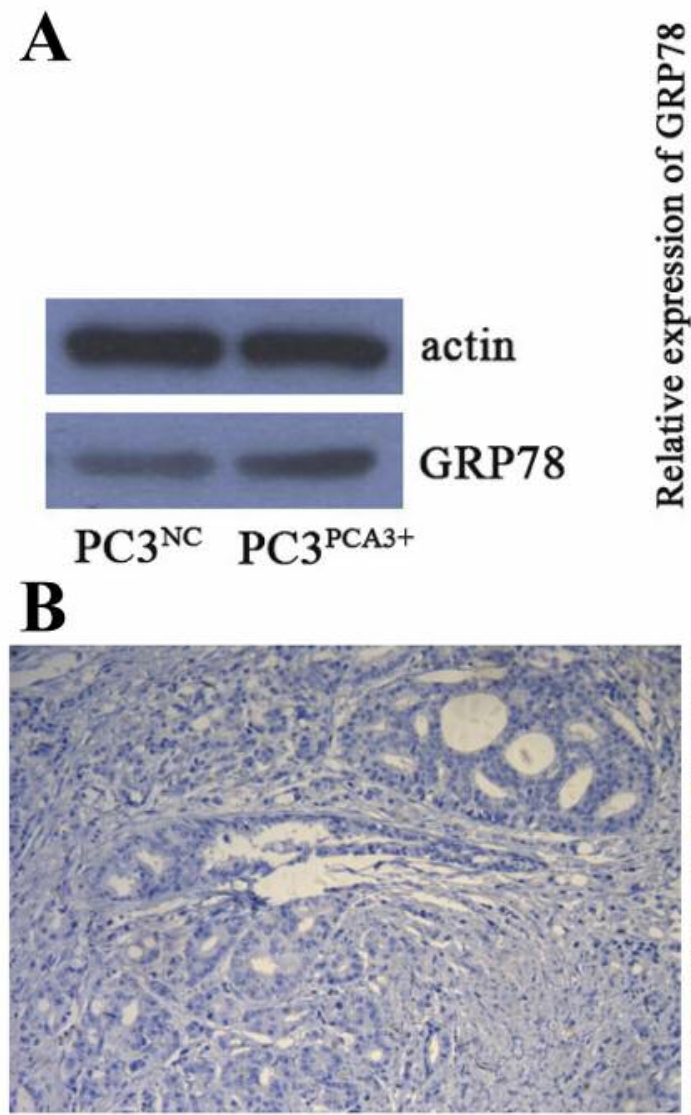

Negative control
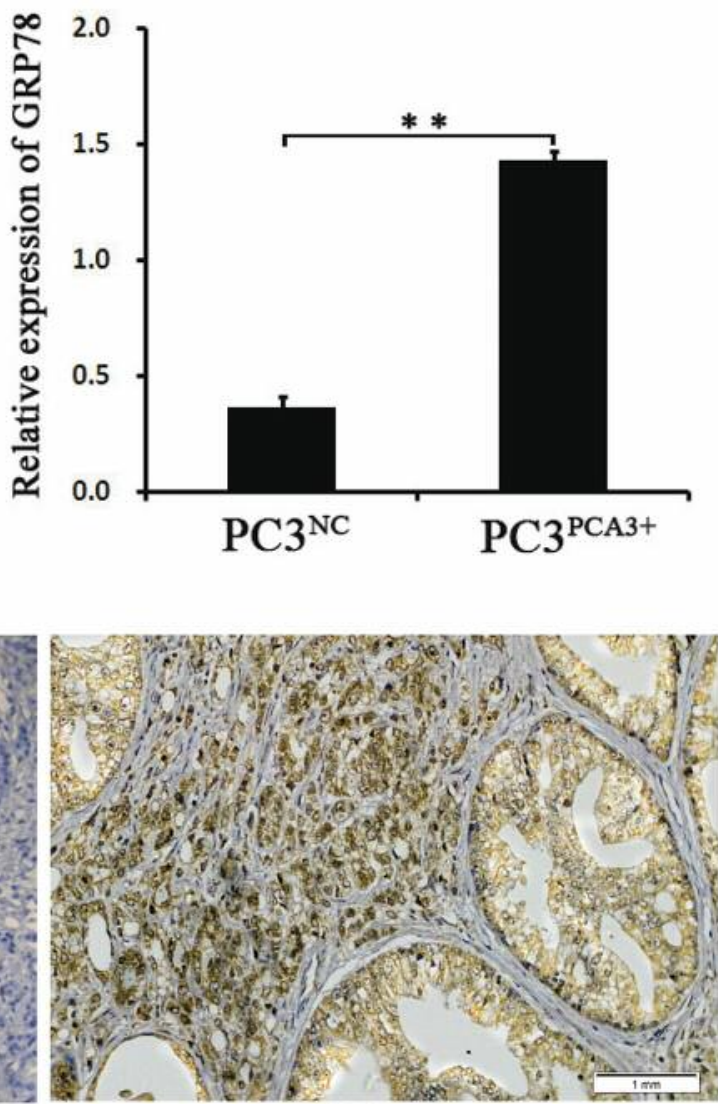

GRP78

Figure 3. Elevated protein level of GRP78 in PCA3-abundant conditions. (A) Western blot showing increased GRP78 expression upon PCA3 overexpression. (B) Immunohistochemistry staining of GRP78 in PCa and adjacent normal tissues.

found to contribute to worse survival for patients with advanced head and neck cancer (23). Positive cell surface GRP78 expression was also associated with improved disease-free survival of breast cancer patients (24). This controversy reflected the complex role that GRP78 plays in the tumorigenesis and progression of tumors. Numerous evidences have also suggested the involvement of GRP78 in the tolerance to chemotherapy. GRP78 expression promoted chemoresistance in pancreatic ductal adenocarcinoma, affected gemcitabine chemosensitivity and apoptosis levels in breast cancer cells $(25,26)$. It also regulated autophagy and apoptosis of ovarian cancer cells by regulating the expressions of beclin1, Bcl-2 and CHOP, thereby affecting the sensitivity to cisplatin in ovarian carcinoma (27).

In terms of $\mathrm{PCa}$, there were a few studies suggesting the involvement of GRP78. GRP78 is highly active in osteoblastic, androgen-independent prostate cancer in vivo (28). Knocking down GRP78 expression suppressed the proliferation, adhesion, migration and induced apoptosis of prostate cancer cells, possibly via maspin and COX-2 regulation $(29,30)$. GRP78 was also reported to be preferentially expressed in the camptothecin (CPT)-resistant PC3 prostate cancer cell line in comparison to the CPTsensitive LNCaP prostate cancer cell line, which indicated its involvement in chemotherapy resistant in PCa (31). In our study, overexpression of PCA3 resulted in increased proliferation and migration of $\mathrm{PCa}$ cells and reduced expression of GRP78. Considering previous findings, it is highly likely that GRP78 is regulated by PCA3 in promoting the development of $\mathrm{PCa}$. PCA3 contributes to the progression of $\mathrm{PCa}$, at least in part, through the upregulation of GRP78.

In conclusion, this study confirmed that elevated PCA3 promotes cell proliferation, migration and invasion while inhibiting cell apoptosis in PCa cell line, possibly in part through up-regulation of GRP78. The interactive relationship between PCA3 and GRP78, as well as other differentially expressed proteins, still awaits further investigation. 


\section{Acknowledgements}

This study was supported by the National Natural Science Foundation of China (grant no. 81402292, 81571490), Shandong Provincial Natural Science Foundation, China (grant no. ZR2014HQ068) and Yantai Science and Technology Development Plan (grant no. 2014WS004, 2015WS024 and 2016WS002).

\section{References}

1 Torre LA, Bray F, Siegel RL, Ferlay J, Lortet-Tieulent J and Jemal A: Global cancer statistics, 2012. CA Cancer J Clin 65: 87-108, 2015.

2 Siegel RL, Miller KD and Jemal A: Cancer statistics, 2016. CA Cancer J Clin 66: 7-30, 2016.

3 Chen W, Zheng R, Baade PD, Zhang S, Zeng H, Bray F, Jemal A, Yu XQ and He J: Cancer statistics in China, 2015. CA Cancer J Clin 66: 115-132, 2016.

4 Rodrigues DN, Butler LM, Estelles DL and de Bono JS: Molecular pathology and prostate cancer therapeutics: From biology to bedside. J Pathol 232: 178-184, 2014.

5 Saini S: PSA and beyond: Alternative prostate cancer biomarkers. Cell Oncol (Dordr) 39: 97-106, 2016.

6 Romero Otero J, Garcia Gomez B, Campos Juanatey F and Touijer KA: Prostate cancer biomarkers: An update. Urol Oncol 32: 252-260, 2014.

7 Bussemakers MJ, van Bokhoven A, Verhaegh GW, Smit FP, Karthaus HF, Schalken JA, Debruyne FM, Ru N and Isaacs WB: DD3: A new prostate-specific gene, highly overexpressed in prostate cancer. Cancer Res 59: 5975-5979, 1999.

8 Gandini O, Luci L, Stigliano A, Lucera R, Di Silverio F, Toscano $\mathrm{V}$ and Cardillo MR: Is DD3 a new prostate-specific gene? Anticancer Res 23: 305-308, 2003.

9 Schalken JA, Hessels D and Verhaegh G: New targets for therapy in prostate cancer: Differential display code 3 (DD3 (PCA3)), a highly prostate cancer-specific gene. Urology 62: 34-43, 2003.

10 Tomlins SA: Urine PCA3 and TMPRSS2: ERG using cancerspecific markers to detect cancer. Eur Urol 65: 543-545, 2014.

11 Hessels D and Schalken JA: The use of PCA3 in the diagnosis of prostate cancer. Nat Rev Urol 6: 255-261, 2009.

12 Filella $\mathrm{X}$ and Foj L: Emerging biomarkers in the detection and prognosis of prostate cancer. Clin Chem Lab Med 53: 963-973, 2015.

13 Ferreira LB, Palumbo A, de Mello KD, Sternberg C, Caetano MS, de Oliveira FL, Neves AF, Nasciutti LE, Goulart LR and Gimba ER: PCA3 noncoding RNA is involved in the control of prostate-cancer cell survival and modulates androgen receptor signaling. BMC Cancer 12: 507, 2012.

14 Lemos AE, Ferreira LB, Batoreu NM, de Freitas PP, Bonamino $\mathrm{MH}$ and Gimba ER: PCA3 long noncoding RNA modulates the expression of key cancer-related genes in LNCaP prostate cancer cells. Tumour Biol 37: 11339-11348, 2016.

15 Görg A, Weiss W and Dunn MJ: Current two-dimensional electrophoresis technology for proteomics. Proteomics 4: 36653685, 2004.

16 Wang W, Wang X, Zhu P, Sun CM, Jin S, Liu J, Li N and Liu J: Expression and location of glucose-regulated protein 78 in testis and epididymis. WIMJ Open 1: 14-17, 2014.

17 Ting $\mathrm{J}$ and Lee AS: Human gene encoding the 78,000-dalton glucose-regulated protein and its pseudogene: Structure, conservation, and regulation. DNA 7: 275-286, 1988.
18 Hendershot LM, Valentine VA, Lee AS, Morris SW and Shapiro DN: Localization of the gene encoding human BiP/GRP78, the endoplasmic reticulum cognate of the HSP70 family, to chromosome 9q34. Genomics 20: 281-284, 1994.

19 Wang M, Wey S, Zhang Y, Ye R and Lee AS: Role of the unfolded protein response regulator GRP78/BiP in development, cancer, and neurological disorders. Antioxid Redox Signal 11: 2307-2316, 2009.

20 Sykes EK, Mactier S and Christopherson RI: Melanoma and the unfolded protein response. Cancers (Basel) 8: pii: E30, 2016.

21 Ulianich L and Insabato L: Endoplasmic reticulum stress in endometrial cancer. Front Med (Lausanne) 1: 55, 2014.

22 Niu Z, Wang M, Zhou L, Yao L, Liao Q and Zhao Y: Elevated GRP78 expression is associated with poor prognosis in patients with pancreatic cancer. Sci Rep 5: 16067, 2015.

23 Kaira K, Toyoda M, Shimizu A, Imai H, Sakakura K, Nikkuni O, Suzuki M, Iijima M, Asao T and Chikamatsu K: Prognostic significance of GRP78/BiPexpression in patients with Stage III/IV hypopharyngeal squamous cell carcinoma. Neoplasma 63: 477-483, 2016.

24 Yerushalmi R, Raiter A, Nalbandyan K and Hardy B: Cell surface GRP78: A potential marker of good prognosis and response to chemotherapy in breast cancer. Oncol Lett 10: 2149-2155, 2015.

25 Gifford JB, Huang W, Zeleniak AE, Hindoyan A, Wu H, Donahue TR and Hill R: Expression of GRP78, master regulator of the unfolded protein response, increases chemoresistance in pancreatic ductal adenocarcinoma. Mol Cancer Ther 15: 1043-1052, 2016.

26 Xie J, Tao ZH, Zhao J, Li T, Wu ZH, Zhang JF, Zhang J and Hu XC: Glucose regulated protein 78 (GRP78) inhibits apoptosis and attentinuteschemosensitivity of gemcitabine in breast cancer cell via AKT/mitochondrial apoptotic pathway. Biochem Biophys Res Commun 474: 612-619, 2016.

$27 \mathrm{Li} \mathrm{M}$, Tian J and Qu Q: Effect of glucose regulated protein 78 on autophagy and apoptosis in ovarian epithelial carcinoma. Zhonghua Fu Chan Ke Za Zhi 50: 848-853, 2015.

28 Mandelin J, Cardo-Vila M, Driessen WH, Mathew P, Navone NM, Lin SH, Logothetis CJ, Rietz AC, Dobroff AS, Proneth B, Sidman RL, Pasqualini R and Arap W: Selection and identification of ligand peptides targeting a model of castrateresistant osteogenic prostate cancer and their receptors. Proc Natl Acad Sci USA 112: 3776-3781, 2015.

29 Lu T, Yang W, Wang Z, Hu Z, Zeng X, Yang C, Wang Y, Zhang Y, Li F, Liu Z, Wang D and Ye Z: Knockdown of glucoseregulated protein 78/binding immunoglobulin heavy chain protein expression by asymmetric small interfering RNA induces apoptosis in prostate cancer cells and attenuates migratory capability. Mol Med Rep 11: 249-256, 2015.

30 Wu CT, Wang WC, Chen MF, Su HY, Chen WY, Wu CH, Chang YJ and Liu HH: Glucose-regulated protein 78 mediates hormoneindependent prostate cancer progression and metastasis through maspin and COX-2 expression. Tumour Biol 35: 195-204, 2014.

31 Hasegawa N, Mizutani K, Suzuki T, Deguchi T and Nozawa Y: A comparative study of protein profiling by proteomic analysis in camptothecin-resistant $\mathrm{PC} 3$ and camptothecin-sensitive LNCaP human prostate cancer cells. Urol Int 77: 347-354, 2006.

Received May 2, 2017

Revised May 28, 2017

Accepted May 29, 2017 